\title{
Research on user experience of smart home under the development of Internet
}

\author{
Yanmin Xue ${ }^{1,}$, Jinying Wang ${ }^{1, b}$, Xuyang Zhang ${ }^{1, c}$ \\ ${ }^{1}$ Department of Industrial Design, Xi'an University of Technology, Xi'an, Shaanxi, 710054, China
}

\begin{abstract}
This paper aims to study the current situation and prospect of user experience of different smart products in smart home under the modern Internet. Through the analysis of the relationship between the user's demand level and smart home, as well as the current situation and problems of existing products in the market, this paper studies the user demand and user experience. It is concluded that to make smart home into every user's home, we need to fully consider the user experience in the design, and pay attention to the user's functional needs, emotional needs and interactive experience needs. Thus, smart home becomes a meaningful home system to help users' lives.
\end{abstract}

\section{Introduction}

With the rapid development of computer technology and electronic communication technology, the concept of EVERTHING CAN BE CONNECTED has been popularized; the arrival of $5 \mathrm{G}$ digital information era provides smart home with high sensitivity, high transmission efficiency and good network stability technology, which can provide users with a higher quality smart home Internet of things system, provide a technical basis for the future development of smart home, and is also full of Meet the needs of users and improve the technical guarantee of use experience. At present, smart home can not provide users with a good experience, and smart home in the market is also different. Therefore, it is necessary to analyze and study the needs of smart home users, and put

forward the design principles and development prospects of corresponding products.

\section{The relationship between user needs and smart home}

Maslow's hierarchy of needs theory divides people's needs into five types: physiological needs, security needs, social needs, respect needs and self transcendence needs ${ }^{[1]}$, which are arranged from the lower level to the higher level. Only when human beings meet the basic physiological and security needs can they explore the level of self transcendence, which also conforms to the demand distribution trend of Maslow's theory, as shown in Figure 1.

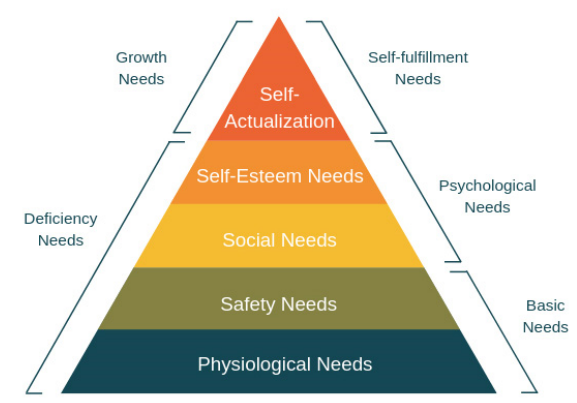

Figure 1. Maslow's hierarchy of needs.

The emergence of smart home has proved the pursuit of self transcendence by users. People are no longer satisfied with the functions of traditional furniture, and pursue more upgraded service consumption and emotional resonance. In essence, smart home is a product connected through the Internet of things, through the collection, analysis and application of terminal data, to meet the needs of users, improve the use experience, and then improve the quality of life. To meet the needs of users is a prerequisite for smart home to develop more vigorously. Any product that does not leave the market needs to respond to the real needs of users ${ }^{[2]}$.

From the initial establishment of the connection between people, to the present development direction of all things can be connected, the Internet is constantly meeting the needs of human beings. According to the bottom-up development mode, it has developed from meeting the social needs, respecting the needs, to self

\footnotetext{
axueym@xaut.edu.cn_b1414487905@qq.com_ ${ }^{\mathrm{c}} 18829028651 @ 163 . c o m$
} 
realization needs. Smart home has changed from complicated wired connection to simple wireless connection due to the innovation of Internet of things technology, which also brings more opportunities for more users to experience and have a smart home.

At present, more and more Internet companies and traditional home appliance giants are laying out smart home appliances, and smart home still has a huge potential market.

\section{User research and analysis of smart home}

At present, the concept of USER CENTERED DESIGN is generally accepted. In the process of product development, it is necessary to first determine the needs and behavior of the target population ${ }^{[3]}$. The main consumer force in today's society has become the post- 80 s and post-90s generation. They are more young and fashionable, pursuing science and technology, and dare to try new products.Growing up in the environment of smart equipment, the post-00s generation is bound to become a generation more brave to explore new things in the future.

People's consumption concept is no longer the same as traditional shopping. In addition to the function, quality or performance of the product itself, people also value the added value of the product and the services that the product can bring to users after purchase. Even though the current market situation of smart home is not mature, the quality and convenience that are inadvertently revealed from the small details are often what really impress consumers. Therefore, the product design of smart home needs to be more in line with user needs and improve user experience.

\section{Analysis of product examples in smart home}

Smart home is an ecological closed system based on family house, which uses high and new technology such as Internet to connect different functional equipment into an integrated system $^{[4]}$. Individual smart home products can not form smart home, but smart home is composed of different smart home individuals. Smart air conditioning, smart washing machine, smart door lock and other smart items can build a smart home system in the same smart ecosystem. This chapter mainly studies the user demand and experience analysis of intelligent single products with different types of functions, represented by smart door lock, smart speaker and smart lighting equipment.

\subsection{Analysis of the user needs and experience of smart door lock}

Door lock is an important guarantee to keep people away from external danger. It can isolate the private space of users and create a comfortable environment for them. Smart door lock has undoubtedly become the first line of defense in the whole smart home system. On the basis of traditional mechanical key, smart door lock adds fingerprint, password, magnetic card, mobile phone and other unlocking methods ${ }^{[5]}$. Fingerprint, password, mobile phone and other ways to unlock the user's identity with digital technology save the user some tedious steps, such as finding the key, taking the key, and avoiding some unexpected situations, such as forgetting to take the key, losing the key, accidentally locking the door outside.

For smart door lock, security is the most important requirement. In June 2018, the event of "small black box" seconds to open the smart door lock made many consumers have doubts about the security of the smart door lock, But according to the existing literature ${ }^{[6][7]}$ that "small black box" can open the smart door lock in seconds. As long as it is a smart door lock produced by a regular brand, consumers can still use it at ease.

Figure 2 shows a new smart push-pull lock recently launched by Xiaomi company at the press conference on June 11, 2019. Using mobile phone to install Mijia APP, you can access your own smart home equipment. The anti pry alarm function, door not closed alarm function and the use of super $\mathrm{C}$ level lock cylinder are all functional guarantee for the safety requirements of users. The intelligent linkage of opening the door and turning on the light is a step forward to meet the emotional needs of users. Press fingerprints $\rightarrow$ Identify success $\rightarrow$ Open the door lock $\rightarrow$ Push the door into the room, It may take only a few seconds to complete this series of actions, greatly upgrading the user experience and eliminating the tedious steps. At the same time, when returning home at night, the lights in the porch can be linked with the door lock, showing an open state, adding a little warmth to the user. The function of viewing the user's access record is also one of the functions of caring for the user as a smart door lock. Table 1 summarizes and compares the functional status of some smart door locks. 


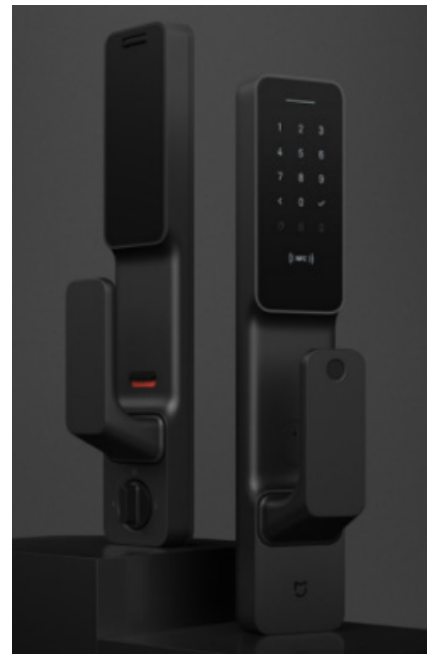

Figure 2. Xiaomi smart lock.

Table 1. Comparison of the functions of four different brands of smart door locks.

\begin{tabular}{ccccc}
\hline & & \multicolumn{3}{c}{ FUNCTIONS } \\
\cline { 3 - 5 } Brand & Smart linkage & APP control & Fingerprint, Password, C+ard unlocking & Other \\
Kaadas K9 & no & yes & yes & Tmall Genie \\
Loock 2S & yes (mijia) & yes & yes & $/$ \\
Haier Eseries & no & yes & yes & $/$ \\
Midea X6 & yes & yes & yes & \\
\hline
\end{tabular}

It can be concluded from table 1 that smart door locks as the entrance of smart home, it is an inevitable trend to link other smart products in the home. The smart door lock can not only guarantee the user's sense of security, but also simplify the operation steps, upgrade the user experience, and provide a good start for the user's smart home life.

\subsection{Analysis of the user needs and experience of smart speaker}

In 2014, Amazon released its first smart speaker echo, becoming the first smart home product to apply smart voice interaction to traditional appliances.

Smart speaker has become a new type of smart home central controller, which has been seized by major

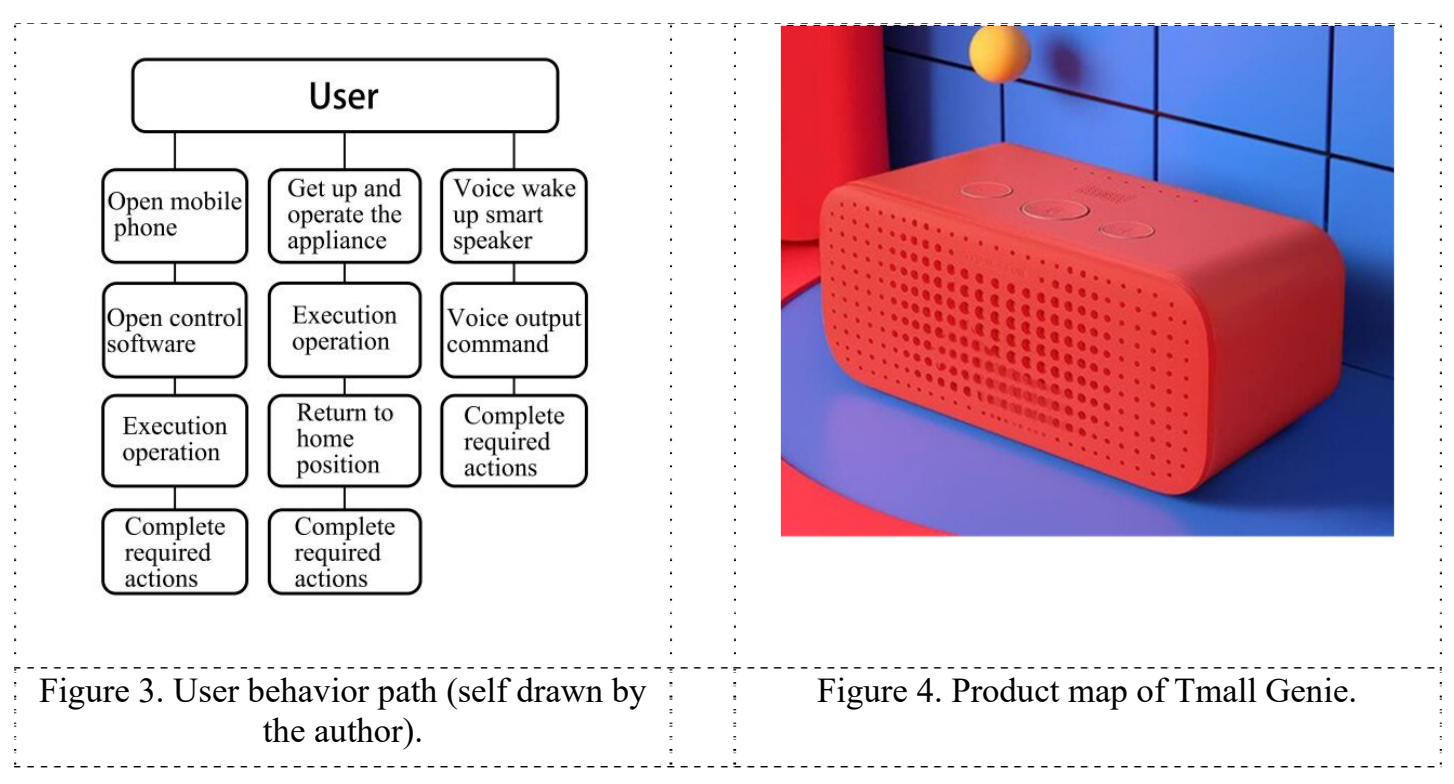

companies as a breakthrough point to open its smart home market. The function of the smart speaker is not only to communicate with people, play music, news, weather and so on, but also to connect with the smart home appliances, so as to achieve the purpose of voice control home appliances. Voice is an efficient way to transmit information. The amount of information that people deliver in ten minutes of voice conversation is about three times that of typing chat. At present, smart speaker control smart home can complete the required operations through the three behavior paths described in Figure 3. It can be seen from Figure 3 that the user can control the audio through voice to complete the required operation, and the voice operation mode simplifies many tedious steps without interrupting the user's current action. 
Figure 4 shows the smart speaker produced by Alibaba, tmall genie, which supports smart home control, voice shopping, mobile phone recharging, take out, audio music playing and other functions. At present, there is less and less communication between people in the society, and people's demand for communication and interaction is not satisfied. The smart speaker can have some simple conversations with people, meet the needs of users for communication and communication, and follow the user's instructions to complete tasks, simplify the user's operation steps, and improve the user experience.

Table 2 summarizes and compares the functional status of some smart speaker systems.

Table 2. Comparison of the functions of four different brands of smart speaker.

\begin{tabular}{ccc}
\hline \multirow{2}{*}{ Brand } & \multicolumn{2}{c}{ FUNCTIONS } \\
\cline { 3 - 3 } & Intelligent home control & Voice dialogue \\
Jing dong DingDong2 & yes & yes \\
Tmall Genie & yes & yes \\
XiaoAi speaker & yes & yes \\
XiaoDu NV6101 & yes & yes \\
\hline
\end{tabular}

It can be concluded from table 2 that as a new smart home central controller, the smart speaker needs to meet the user's interaction needs and control the smart home to complete the response instructions. For intelligent operation, it is the most basic demand function, and there is more room for the development of smart speaker functions.

\subsection{Analysis of user needs and experience of smart lighting equipment}

Lighting is an indispensable part of people's life. Artificial lighting is needed to supplement the lighting when there is not enough light in the day and no sunshine at night, so as to meet human activities. With the improvement of living standards and the pursuit of high quality of life details, people are not satisfied with the single function of lighting, start to pursue the application of different lights in different scenes. The traditional lighting mode can't meet people's life needs, and the intelligent lighting field inevitably starts to produce and develop.Connecting the lighting equipment into the smart home system, so that people can adjust the brightness and color of the light at any time according to their own needs, so as to provide a more comfortable lighting environment for people's daily life becomes more and more popular ${ }^{[8]}$.

Figure 5 shows a smart ceiling lamp produced by Midea, which can be controlled by its Xiaomei speaker products. When users give instructions to adjust the brightness and temperature of the light, they can quickly respond and adjust. Lights of different colors and brightness can meet the needs of people's rest, reception, entertainment and other use scenarios. The control method is not single, you can choose remote control, wall switch, intelligent speaker, etc., which can meet the basic needs of current users. Table 3 summarizes the functional comparison of some current smart lighting equipment.

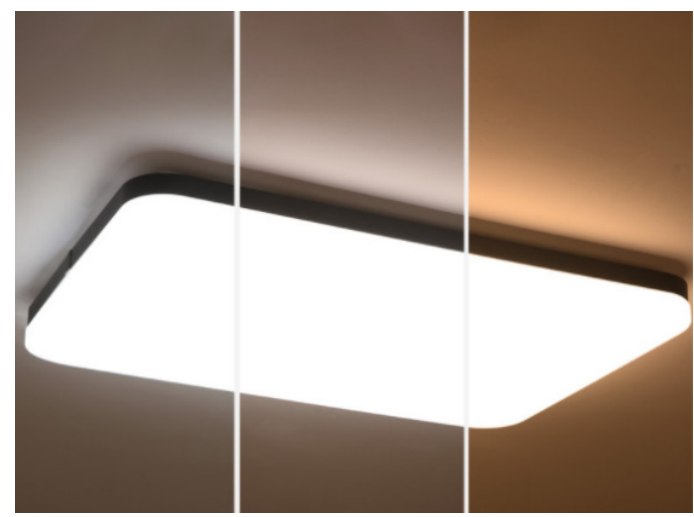

Figure 5. Meidi smart lighting ceiling lamp.

Table 3. Comparison of the functions of four different brands of smart lighting equipment.

\begin{tabular}{ccccc}
\hline Brand & \multicolumn{4}{c}{ FUNCTIONS } \\
\cline { 4 - 5 } & Intelligent control & Timing control & Remote control & General switch \\
\cline { 4 - 5 } NVC NX096 & yes (Tmall Genie) & no & yes & yes \\
Philiph YueHeng & no & yes & yes & yes \\
Panasonic & yes (Tmall Genie) & no & yes & yes \\
Meidi & yes (XiaoMei speaker) & no & yes & yes \\
\hline
\end{tabular}


It can be seen from table 3, but in terms of the current situation of intelligent lighting, the field of intelligent lighting is still in the initial stage of development. Facing the new needs of users, we need to continue to research and explore. The future development of smart lighting equipment has a certain prospect.

\subsection{Conclusion of smart home products}

Only from the real needs of users, the smart products to solve practical problems for people is a smart product. In pursuit of intelligence, simple in the product and add a screen or make the product to be able to connect to the Internet, this is just to stay at the level of "The surface of the smart", doesn't really meet the needs of users, upgrade the user experience, but because of the increasing number of "The surface of the smart" raised the cost of production, causing unnecessary economic burden to users.

\section{Conclusion}

Smart application to more and more home appliance scenes is the inevitable result of technology and era development, but also the inevitable result required by users. People's pursuit of life details and experience makes more household products become intelligent. However, now the smart household brands in the market are systematic and incompatible, so there are certain limitations in brand selection, which has a certain negative impact on the realization of more users pursuing smart household.

In order to achieve smart performance, it is impossible to only add screen or networking functions to the product itself. In the design, user experience should be fully considered and users' functional needs, emotional needs and interactive experience needs should be paid attention to, so as to make the product a truly meaningful and helpful smart product for users' life. Only by deeply understanding user needs and improving user experience can we grasp the priority of future smart home and realize real smart home as soon as possible.

\section{Acknowledgments}

This paper was supported by Chinese Ministry of education of Humanities and Social Science (project No. 17YJAZH100) and Humanities and Social Science Program of Shaanxi Province (Project No. 2018K13).

\section{References}

1. YANG Guang.(2019)Smart Home Needs to Return to Users' Needs. N.Qingdao Daily, 201908-21(006).

2. YANG Jun-hui.(2018)Research on the Application of Internet of Things Technology in the Development of Smart Home.J.Information Technology and Informatization,05:119-121.
3. LIU Li-jun.(2016)A Survey of User Experience Research in Product Interaction Design.J.Science and Technology and Innovation, 11:28.

4. ZHU Pei-ju,LING Zong-miu,HE Shu.(2019)Current Situation and Safety Protection of Intelligent Door Lock Products.J.Quality and Standardization, 01:46-48.

5. QIAN Jun-jie,LING Yong-ming,LIAO Liang.(2018)Discussion on the Influence of Tesla Coil on Intelligent Door Lock.J.Electrical Appliances, 10:11-14.

6. HOU Ting-ting.(2019)Smart Door Lock: Can Security Keep Up?.J.Electrical Appliances.07:44.

7. (2018)The Phenomenon of "Small Black Box" Opening Intelligent Lock in Seconds.J.China Security Protection Technology And Application.04:17-18.

8. HUANG Weng-jian.(2017)Research on LED Intelligent Lighting Based on Home Scene.D.South China University of Technology. 